\title{
A randomized noninferiority trial of condensed protocols for genetic risk disclosure of Alzheimer's disease
}

\author{
Robert C. Green $^{\mathrm{a}, \mathrm{b}, *}$, Kurt D. Christensen ${ }^{\mathrm{a}}$, L. Adrienne Cupples ${ }^{\mathrm{c}}$, Norman R. Relkin ${ }^{\mathrm{d}}$, \\ Peter J. Whitehouse ${ }^{\mathrm{e}}$, Charmaine D. M. Royal ${ }^{\mathrm{f}}$, Thomas O. Obisesan ${ }^{\mathrm{g}}$, Robert Cook-Deegan ${ }^{\mathrm{h}}$, \\ Erin Linnenbringer ${ }^{\mathrm{i}}$, Melissa Barber Butson ${ }^{\mathrm{e}}$, Grace-Ann Fasaye ${ }^{\mathrm{j}}$, Elana Levinson ${ }^{\mathrm{k}}$, \\ J. Scott Roberts ${ }^{1}$, for the REVEAL Study Group ${ }^{1}$ \\ ${ }^{a}$ Division of Genetics, Department of Medicine, Brigham and Women's Hospital and Harvard Medical School, Boston, MA, USA \\ ${ }^{b}$ Partners Personalized Medicine, Boston, MA, USA \\ ${ }^{c}$ Departments of Biostatistics and Epidemiology, Boston University School of Public Health, Boston, MA, USA \\ ${ }^{d}$ Department of Neurology, Weill Medical College of Cornell University, New York, NY, USA \\ ${ }^{e}$ Department of Neurology, Case Western Reserve University, Cleveland, OH, USA \\ ${ }^{f}$ Department of African and African American Studies, Duke University, Durham, NC, USA \\ ${ }^{g}$ Department of Medicine, Howard University School of Medicine, Washington, DC, USA \\ ${ }^{h}$ Sanford School of Public Policy, Duke University, Durham, NC, USA \\ ${ }^{i}$ Division of Public Health Sciences, Department of Surgery, Washington University School of Medicine, St. Louis, MO, USA \\ ${ }^{j}$ Walter Reed National Military Medical Center, Bethesda, MD, USA \\ ${ }^{k}$ Department of Surgery, Columbia University, New York, NY, USA \\ ${ }^{l}$ Department of Health Behavior and Health Education, University of Michigan School of Public Health, Ann Arbor, MI, USA
}

Abstract

Introduction: Conventional multisession genetic counseling is currently recommended when disclosing apolipoprotein $\mathrm{E}$ ( $A P O E$ ) genotype for the risk of Alzheimer's disease (AD) in cognitively normal individuals. The objective of this study was to evaluate the safety of brief disclosure protocols for disclosing $A P O E$ genotype for the risk of $\mathrm{AD}$.

Methods: A randomized, multicenter noninferiority trial was conducted at four sites. Participants were asymptomatic adults having a first-degree relative with AD. A standard disclosure protocol by genetic counselors (SP-GC) was compared with condensed protocols, with disclosures by genetic counselors (CP-GC) and by physicians (CP-MD). Preplanned co-primary outcomes were anxiety and depression scales 12 months after disclosure.

Results: Three hundred and forty-three adults (mean age 58.3, range 33-86 years, $71 \%$ female, $23 \%$ African American) were randomly assigned to the SP-GC protocol $(n=115)$, CP-GC protocol $(\mathrm{n}=116)$, or CP-MD protocol $(\mathrm{n}=112)$. Mean postdisclosure scores on all outcomes were well below cut-offs for clinical concern across protocols. Comparing CP-GC with SP-GC, the $97.5 \%$ upper confidence limits at 12 months after disclosure on co-primary outcomes of anxiety and depression ranged from a difference of 1.2 to 2.0 in means (all $P<.001$ on noninferiority tests), establishing noninferiority for condensed protocols. Results were similar between European Americans and African Americans. Conclusions: These data support the safety of condensed protocols for $A P O E$ disclosure for those free of severe anxiety or depression who are actively seeking such information.

(C) 2015 The Alzheimer's Association. Published by Elsevier Inc. All rights reserved.

\footnotetext{
${ }^{1}$ Additional members of the Risk Evaluation and Education for Alzheimer's Disease (REVEAL) Study Group are listed at the end of the manuscript.
}

\footnotetext{
*Corresponding author. Tel.: +1-617-264-5834 (office); Fax: +1-617-

E-mail address: rcgreen@genetics.med.harvard.edu
} 264-3018. 


\section{Introduction}

The $\varepsilon 4$ allele of apolipoprotein $\mathrm{E}(\mathrm{APOE})$ is a common and robust risk factor for Alzheimer's disease (AD), carried by approximately $25 \%$ of the population. In the Risk Evaluation and Education for Alzheimer's Disease (REVEAL) Study, we have utilized the model of disclosing APOE genotype for the risk of $\mathrm{AD}$ to explore translational questions associated with genetic risk disclosure. In a previous randomized controlled trial, we demonstrated that disclosing $A P O E$ genotypes with an extended counseling protocol was not associated with increased anxiety, depression, or distress [1]. The predisclosure counseling in that trial followed what were later published as official recommendations for the genetic risk assessment of $\mathrm{AD}$, and that were based on Huntington Disease (HD) Society of America's Guidelines for Genetic Testing for Huntington Disease [2], a protocol that the recommendations called the "gold standard for genetic testing for adult onset conditions" [3]. Briefly, this protocol includes two pretest and one or more posttest genetic counseling sessions conducted in person and incorporates both neurologic and psychiatric evaluations. Sessions address the physical, psychological, social, and family history factors that may influence the decisionmaking process to ensure informed decision making about testing while minimizing the risks of adverse psychological outcomes [3].

In this report, we describe a separate trial in which all subjects received $A P O E$ disclosure, but were randomized into one protocol that followed the gold standard above, or into one of two protocols with highly condensed pretesting education and counseling. We hypothesized that subjects receiving the condensed protocols with disclosure from a genetic counselor (CP-GC) would show no greater anxiety or depression than subjects receiving the standard protocol 1 year after disclosure.

\section{Methods}

\subsection{Study population and instruments}

We recruited cognitively normal adult first-degree relatives (FDRs) of patients with $\mathrm{AD}$ through mailings to research registries, referrals from collaborating physicians, advertisements in local newspapers, and community outreach at senior centers and nursing homes. We excluded individuals with two or more affected FDRs and individuals from families where the average $A D$ onset age was under 60 years. We screened out individuals who demonstrated potential memory problems by scoring lower than an education-adjusted 87 on the Modified Mini-Mental State Examination [4] and individuals with very severe anxiety and depression, as defined below. We selected European Americans or African Americans for enrollment because we had sufficient data to create ethnicity-specific risk models for these groups that incorporated $A P O E$ genotype [5]. Given ambiguous data about the relationship between $A P O E$ and $\mathrm{AD}$ for other ethnicities [6,7], however, we excluded other populations.

The co-primary outcomes were validated self-report scales of anxiety and depression at 12 months after disclosure. We measured anxiety using the 21-item Beck Anxiety Inventory (BAI) [8] and depression using the 20-item Center for Epidemiological Studies-Depression Scale (CES-D) [9]. BAI scores can range from 0 to 63 , with scores greater than 15 indicating moderate anxiety and scores greater than 25 indicating severe anxiety. CES-D scores can range from 0 to 60 , with scores 16 or greater indicating moderate depression and scores greater than 26 indicating severe depression [10]. Test-related distress at 12 months after disclosure served as a secondary outcome, measured using the Impact of Event Scale (IES) [11], a 15-item self-report instrument commonly used in genetic disclosure research [12]. The IES assessed the frequency of intrusive and avoidance thoughts related to the genetic risk assessment over the past week, with scores of $0-5$ on individual items summed to create an overall score (range 0-75, scores 20 or above indicating significant distress). Because the IES measures distress specific to genetic risk disclosure, it was administered only after testing. We also evaluated secondary outcomes of BAI, CES-D, and IES scores at 6 weeks and 6 months after the disclosure of genetic risk information.

\subsection{Study design}

As described more fully in prior publications $[1,13]$, the multidisciplinary REVEAL Study group designed the study protocol and risk disclosure procedures, including, for this trial, specific risk curves for African American subjects [5]. The study was designed as a noninferiority trial, despite inherent limitations of this approach [14], because the goal of the study was to develop a protocol that markedly reduced clinical service demands rather than one that improved outcomes that had already been shown to be safe [1]. The study was conducted at sites in academic medical centers in Boston, Cleveland, New York, and Washington, DC. An independent external Ethics and Safety Board (ESB), and institutional review boards at each study site, oversaw the protocol and consent development. Subjects provided informed consent by telephone at the time of study enrollment, then again in writing before the blood draw for genotyping. The overall design of the study is shown in Fig. 1.

Following an initial phone interview, subjects were block randomized equally into one of three treatment arms, within strata defined by site, age ( $<60$ vs $\geq 60$ ), race, and gender. In the reference protocol, pretest education and counseling took place with a genetic counselor (the SP-GC arm) [2]. Participants attended a semistructured 35 minute in-person education session with a genetic 


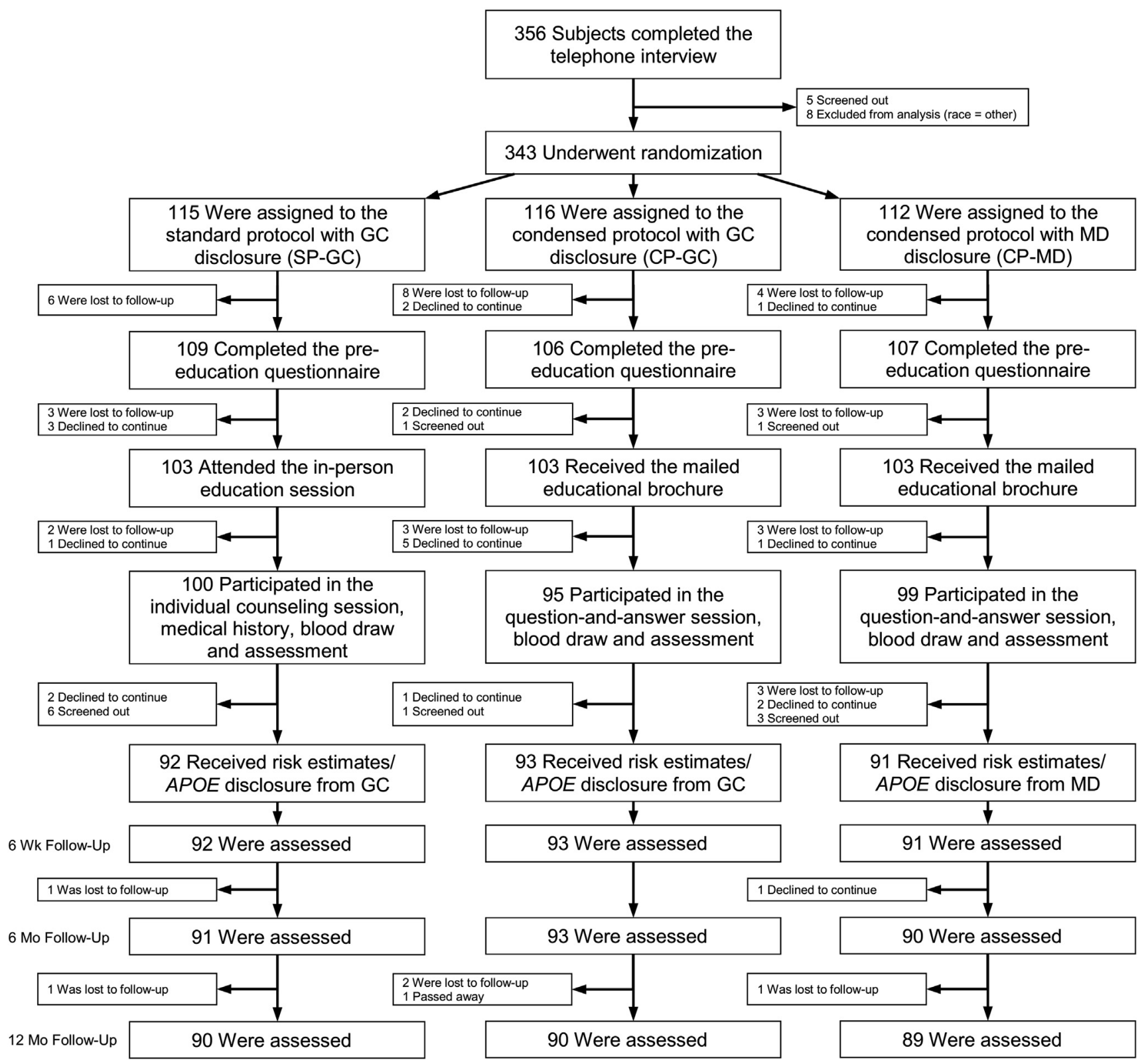

Fig. 1. Study flowchart.

counselor that included: a formal definition of $\mathrm{AD}$, an overview of risk factors for AD (e.g., age, family history), and the level of risk in the general population; an explanation of $A P O E$ and its implications for risk of $\mathrm{AD}$; a description of procedures involved in $A P O E$ testing; a preview of what would be provided in their risk assessment (e.g., risk figures and their format); and a summary of known benefits, risks, and limitations of $A P O E$ testing. At the blood-draw visit, a genetic counselor collected and reviewed the subject's family history of dementia and personal medical information, and proactively addressed psychosocial aspects of testing. In the two condensed protocols the in-person education session was replaced with a mailed brochure (see Supplementary
Fig. 1), and subjects provided family history and medical information on mailed forms. When blood was drawn in the condensed protocols, genetic counselors reviewed the family history and medical information subjects mailed back and responded to participant questions rather than proactively addressing the psychosocial aspects of testing. The two condensed protocols differed only in who was doing the disclosure. $A P O E$ was genotyped at Athena Diagnostics, a facility certified by the Clinical Laboratory Improvement Amendments (CLIA).

Approximately 1 month after the blood draw, subjects received their $A P O E$ genotypes and numerical $\mathrm{AD}$ risk assessments as previously described [1,5,15]. In brief, all subjects were shown a single graph with gender and 
race-specific risk curves and were told their $A P O E$ genotype and numeric estimates of their cumulative lifetime (potential range: $13 \%-77 \%$ ) and remaining risk for $\mathrm{AD}$ (cumulative incidence from current age to the age of 85 years). A genetic counselor disclosed results to subjects in the SP-GC arm and in one condensed protocol arm (CP-GC), while a study physician disclosed results in the other condensed protocol arm (CP-MD). The four physicians doing the disclosure were specialists in dementia, but had received no formal training in genetic counseling.

Study staff administered the BAI and CES-D before the blood draw (baseline) and at all follow-up time points. The IES was administered only at follow-up time points. The ESB reviewed the protocol, monitored study progress, and established criteria for adverse event reporting. An immediate interview was planned for any subjects whose BAI or CES-D scores exceeded 26 or increased by more than 15 points from baseline at any point in the study. Cases of concern to the clinical teams were discussed in monthly phone calls. The chair of the ESB reviewed aggregated results annually. This trial was registered with clinicaltrials. gov identifier NCT00089882.

\subsection{Statistical analysis}

We used analysis of variance (ANOVA) and chi-square testing to compare demographic features of the randomized groups. We compared discontinuation rates and subject variables associated with discontinuation across protocols using t-tests and chi-square tests. ANOVA was used to compare session lengths across protocols.

In estimating the power for the primary analysis, we followed recommendations [16] for defining noninferiority as occurring if the upper limits of one-sided $97.5 \%$ confidence intervals (equivalent to upper bounds of two-sided 95\% CIs) for mean differences between protocols were less than a prespecified margin of 5 points on each of the outcome scales, the same intervals used in analyses for the initial REVEAL Study trial [1]. In comparing co-primary outcomes of BAI and CES-D scores in the SP-GC vs CP-GC arms at 12 months, we estimated that we had more than $90 \%$ power at $\alpha=0.05 / 2$ (for the two co-primary outcomes) $=0.025$ to confirm noninferiority within this margin.

To test the primary hypothesis of noninferiority between SP-GC and CP-GC, postdisclosure levels of the two coprimary outcomes (BAI and CES-D) were evaluated at 12 months for noninferiority first using linear models, with no adjustment for potential confounders; and second using linear models adjusting for age, gender, education, baseline scores, and $A P O E$ genotype. Because these measures were skewed with a floor effect at zero, we also conducted pairwise Wilcoxon Rank Sum tests with no adjustment for covariates, and with Tobit models adjusting for the same covariates as the linear regression models. Secondary analyses comparing the noninferiority of the CP-MD protocol to the SP-GC and CP-MD protocols mirrored these analyses.
$P$ values for these analyses were calculated from one-sided noninferiority tests assuming that scores on a condensed protocol were not more than 5 points higher than the comparison protocol.

In addition to assessing co-primary outcomes at 12 months, we conducted secondary analyses to examine the outcomes at the baseline visit (posteducation predisclosure) and at the 6-week and 6-month postdisclosure visits. Both condensed protocols were identical through the baseline visit, so data in these two arms were combined on multiple linear regression analyses of predisclosure outcomes, adjusting for age, gender, race, and education. We conducted both intention-to-treat (ITT) and per-protocol analyses on predisclosure data because ITT analyses can bias interpretation in noninferiority studies $[16,17]$. Only per-protocol analyses were conducted and reported on postdisclosure data because we could not reliably impute $A P O E$ genotypes, which were needed for adjusted analyses. $P$ values for comparisons of baseline, predisclosure scores were calculated from tests that mean scores for the condensed protocols were not equivalent to mean scores for the standard protocol. $P$ values for secondary postdisclosure analyses were calculated from one-sided noninferiority tests that scores on a condensed protocol were not more than 5 points higher than a comparison protocol.

Interactions between randomization arm and $A P O E$ genotype were omitted from final models because they failed to reach significance at $P \leq .05$. For both pre- and postdisclosure analyses, missing values were imputed with the Markov chain Monte Carlo method of multiple imputation using PROC MI statistical software, version 9.3 (SAS Institute). Variables to calculate joint probabilities for multiple imputation were selected using an inclusive strategy, and included all variables used in analyses and additional variables whose sole purpose in these analyses were to improve the performance of the imputation models [18]. These additional variables were collected through self-report in the phone interview, pre-education, and follow-up questionnaires, and included income, AD risk perceptions, and less proven measures of test-related affect [19]. We also evaluated the CP-MD protocol and the CP-GC protocol on all outcomes using the procedures described above and controlling for baseline scores where applicable.

\section{Results}

Of the 356 subjects who completed the introductory telephone interview, five subjects were screened out because on further review, their family history of $\mathrm{AD}$ did not meet eligibility requirements and eight were excluded because they self-identified as other than European American or African American and were told their numeric risk estimates could not be estimated accurately. Ultimately, $96 \%$ were randomized and analyzed (Fig. 1). Of 343 subjects who were randomized, 20 (5.8\%) subjects declined to continue in the study for the following nonexclusive reasons: study demands (9), concerns about anticipated emotional 
responses to test results (7), or potential discrimination (3), limitations of test information (3), lack of interest (2), lack of AD prevention options (1), and personal health problems (1). Thirty-five (10.2\%) others discontinued without explanation (were lost to follow-up) before disclosure. We also screened out the following during the trial, but before genetic risk disclosure: two individuals whose family history of $\mathrm{AD}$ did not meet eligibility requirements after further review by genetic counselors; one participant who suggested that testing might influence a future decision to pursue suicide; three subjects with cognitive scores below eligibility criteria; and six subjects with depression scores above our prespecified threshold. Demographic characteristics for participants included in the ITT analysis did not vary by randomization arm (Table 1) and were similar to those of the prior trial [1] except for the higher percentage of African Americans in this trial. Ultimately, 276 (80.5\%) of the subjects initially randomized received AD risk assessments with $A P O E$ genotype disclosure.

Whether a subject received their pretest education through a genetic counselor (SP-GC arm) or through a brochure (CP-GC and CP-MD arms) did not affect the likelihood that the subject would drop out of the protocol $(P=.88)$. However, African American ethnicity $(P<.01)$ and lower education $(P<.01)$ were significantly associated with a greater likelihood of dropout before disclosure. At the predisclosure assessment, subjects in all arms scored well below cut-offs for clinical concern on the three outcomes.

Predisclosure education sessions were structured to last approximately 35 minutes in length within the SP-GC arm and did not occur in the $\mathrm{CP}$ arms where a brochure was sent instead. In the SP-GC arm the blood-draw visit, including counseling, averaged 20.3 minutes in length, while the blood-draw visits with question-and-answer only averaged 13.2 minutes across the $\mathrm{CP}$ arms $(P<.001)$. Genetic risk disclosure sessions averaged 22.4 minutes in the SPGC arm, 23.2 minutes in the CP-GC arm, and 18.7 minutes in length in the CP-MD arm $(P<.001)$. At the predisclosure (blood draw) visit where anxiety and depression scales were administered for the first time, the ITT analysis of difference in means between subjects in the standard and condensed protocols was $0.1(95 \% \mathrm{CI}-1.2$ to $1.0, P=.87)$ on the BAI and $0.7(95 \% \mathrm{CI}-0.9$ to $2.3, P=.40)$ on the CES-D. Non-ITT analyses were similar (see Supplementary Table 1).

Table 2 summarizes the unadjusted analysis of primary and secondary study outcomes (adjusted analyses are presented in Supplementary Table 2). All scores were well below standard cut-offs for clinical concern, regardless of disclosure protocol. Two-sided 95\% CIs for the mean difference between the SP-GC and both the CP-GC and CP-MD arms at 12 months after risk estimation and $A P O E$ genotype disclosure were below the predefined 5-point margin of noninferiority for all scales. Secondary analyses also showed noninferiority of both condensed protocols at earlier time points on anxiety and depression, and for the CP-GC protocol on test-related distress 12 months postdisclosure compared with the SP-GC. However, noninferiority could not be demonstrated on test-related distress 6 weeks and 6 months postdisclosure for the CP-MD protocol. Similarly subanalyses supported noninferiority of the CP-MD protocol compared with the CP-GC protocol on anxiety and depression measures, but higher test-related distress scores were noted in the CP-MD protocol at the 6-week ( $\Delta=2.8,95 \%$ $\mathrm{CI}=0.4$ to 5.1 , noninferiority $P=.03$ ) and 6-month $(\Delta=3.0,95 \% \mathrm{CI}=0.5$ to 5.4 , noninferiority $P=.05)$ postdisclosure time points (see Supplementary Table 2).

Table 1

Characteristics of participants in ITT analyses*

\begin{tabular}{|c|c|c|c|c|}
\hline Characteristic & $\begin{array}{l}\text { Standard protocol, } \\
\text { GC disclosure }(\mathrm{n}=115)\end{array}$ & $\begin{array}{l}\text { Condensed protocol, } \\
\text { GC disclosure }(\mathrm{n}=116)\end{array}$ & $\begin{array}{l}\text { Condensed protocol, MD } \\
\text { disclosure }(\mathrm{n}=112)\end{array}$ & $P$ \\
\hline Age: yrs & & & & .94 \\
\hline Range & $36-78$ & $33-86$ & $36-86$ & \\
\hline Female sex: $\mathrm{n}(\%)$ & $79(69)$ & $84(72)$ & $82(73)$ & .72 \\
\hline African American race: $\mathrm{n}(\%)^{\dagger}$ & $27(23)$ & $28(24)$ & $24(21)$ & .88 \\
\hline Range & $9-20$ & $3-20$ & $5-20$ & \\
\hline Currently married: $\mathrm{n}(\%)$ & $65(57)$ & $62(53)$ & $68(61)$ & .54 \\
\hline Site: $\mathrm{n}(\%)$ & & & & 1.00 \\
\hline Boston & $38(33)$ & $38(33)$ & $37(33)$ & \\
\hline Cleveland & $25(22)$ & $25(22)$ & $22(20)$ & \\
\hline Washington, DC & $23(20)$ & $24(21)$ & $21(19)$ & \\
\hline
\end{tabular}

Abbreviations: ITT, intent-to-treat; CP, condensed protocol; GC, genetic counseling; MD, physician.

* $P$ values represent a test that randomization arms differed. Plus-minus values are means \pm standard deviations.

${ }^{\dagger}$ Race was self-reported.

${ }^{\ddagger}$ Including nonfirst degree relatives (e.g., grandparent or cousin). 
Table 2

Unadjusted anxiety, depression, and test-related distress scores by randomization arm, stratified by outcome and time after APOE genotype disclosure*

\begin{tabular}{|c|c|c|c|c|c|c|c|}
\hline & SP-GC $(n=92)$ & CP-GC $(n=93)$ & $\mathrm{CP}-\mathrm{MD}(\mathrm{n}=91)$ & CP-GC vs SP-GC (95\% CI) & $P$ & CP-MD vs SP-GC (95\% CI) & $P$ \\
\hline \multicolumn{8}{|c|}{12 month outcomes } \\
\hline $\mathrm{BAI}^{\dagger}$ & $3.0 \pm 0.5$ & $3.7 \pm 0.5$ & $3.9 \pm 0.5$ & $0.7(-0.7$ to 2.0$)$ & $<.001$ & $0.9(-0.5$ to 2.2$)$ & $<.001$ \\
\hline CES-D & $6.2 \pm 0.6$ & $5.6 \pm 0.6$ & $6.9 \pm 0.6$ & $-0.6(-2.4$ to 1.2$)$ & $<.001$ & $0.6(-1.1$ to 2.4$)$ & $<.001$ \\
\hline \multicolumn{8}{|c|}{6 month outcomes } \\
\hline BAI & $3.2 \pm 0.5$ & $3.1 \pm 0.5$ & $4.4 \pm 0.5$ & $-0.2(-1.6$ to 1.2$)$ & $<.001$ & $1.2(-0.3$ to 2.6$)$ & $<.001$ \\
\hline CES-D & $6.3 \pm 0.7$ & $5.8 \pm 0.7$ & $8.1 \pm 0.7$ & $-0.5(-2.4$ to 1.5$)$ & $<.001$ & $1.8(-0.1$ to 3.8$)$ & .002 \\
\hline BAI & $2.6 \pm 0.5$ & $3.6 \pm 0.5$ & $4.3 \pm 0.5$ & $0.9(-0.4$ to 2.3$)$ & $<.001$ & $1.7(0.3$ to 3.0$)$ & $<.001$ \\
\hline CES-D & $5.7 \pm 0.7$ & $5.8 \pm 0.7$ & $8.1 \pm 0.7$ & 0.1 ( -1.9 to 2.0$)$ & $<.001$ & $2.4(0.4$ to 4.3$)$ & .008 \\
\hline IES & $2.8 \pm 0.9$ & $5.1 \pm 0.9$ & $8.2 \pm 0.9$ & $2.3(-0.1$ to 4.8$)$ & .033 & $5.4(3.0$ to 7.9$)$ & .724 \\
\hline
\end{tabular}

Abbreviations: SP-GC, standard protocol, genetic counseling; CP-GC, condensed protocol, genetic counseling; CP-MD, condensed protocol, physician.

NOTE. $P$ values represent a one-sided noninferiority test, using linear models, that scores on a specific condensed protocol are not more than 5 points higher than the control standard protocol.

*Plus-minus values are means \pm standard errors. CI are two-sided $95 \%$ confidence intervals.

${ }^{\dagger}$ Scores on the Beck Anxiety Inventory (BAI) range from 0 to 63, with higher scores indicating greater anxiety.

${ }^{\ddagger}$ Scores on the Center for Epidemiological Studies Depression Scale (CES-D) range from 0 to 60, with higher scores indicating greater depression.

${ }^{\S}$ Scores on the Impact of Event Scale (IES) range from 0 to 75 , with higher scores indicating greater test-related distress.

Pairwise Wilcoxon Rank Sum tests comparing the CP-GC to the SP-GC and comparing the CP-MD to the SP-GC, with no adjustment for covariates, and with Tobit models adjusting for the same covariates as the linear regression models, were conducted and the results were consistent with the linear regression models (data not shown).

Overall, $26 \%$ of study subjects reported moderate anxiety (BAI $\geq 16$ ), depression (CES-D $\geq 16$ ), or test-related distress (IES $\geq 20$ ) at one or more follow-up time points, with no differences by randomization arm $(P=.23)$. Secondary analyses did not show significant interaction by race, $A P O E$ status, or randomization arms on BAI and CES-D scores at 12 months $(P \geq .27)$. Secondary analyses were also conducted to compare $\varepsilon 4$-positive and negative subjects as shown in Table 3. As previously described in the initial REVEAL Study trial [1], we also found in this trial that $\varepsilon 4$-positive subjects showed no more symptoms of general anxiety or depression than $\varepsilon 4$-negative subjects, but did show greater test-specific distress at all follow-up time points that was clinically trivial, but statistically significant (IES $\Delta=4.9$ at 6 weeks, 3.0 at 6 months, and 2.4 at 12 months, all $P \leq .01$ ).

\section{Discussion}

This trial compares the impact of different disclosure protocols for $A P O E$ genotype. In comparisons between the standard and condensed protocols where both were delivered by genetic counselors, volunteer subjects randomized to receive a condensed protocol did not experience greater anxiety or depression symptoms, nor greater test-related distress, 12 months after disclosure. Noninferiority could not be demonstrated for the secondary outcome of test-related distress at earlier time points, but these differences were still minor. Our findings, in conjunction with prior analyses showing no decreases in knowledge or information recall after receiving the condensed protocols [20], add weight to suggestions that genetic susceptibility test providers may be able to streamline protocols for persons volunteering for such information without compromising their wellbeing, at least when results are disclosed by a genetic counselor. The condensed protocols we used required one less in-person appointment and saved considerable clinician time, substantially reducing the demands of testing on

Table 3

Differences on study outcomes between $A P O E$ \&4-positive and $\varepsilon 4$-negative subjects, stratified by outcome and time after $A P O E$ genotype and $\mathrm{AD}$ risk disclosure

\begin{tabular}{|c|c|c|c|c|c|c|}
\hline & Anxiety (BAI) & & Depression (CES-D) & & Test-related distress (IES) & \\
\hline $12 \mathrm{mo}$ & $0.2(-0.9$ to 1.4$)$ & .69 & $-0.3(-1.8$ to 1.3$)$ & .74 & $2.4(0.6$ to 4.2$)$ & .01 \\
\hline $6 \mathrm{wk}$ & $0.4(-0.8$ to 1.5$)$ & .55 & $0.5(-1.2$ to 2.2$)$ & .55 & $4.9(2.9$ to 6.9$)$ & $<.01$ \\
\hline
\end{tabular}

Abbreviations: CES-D, Center for Epidemiological Studies Depression Scale; BAI, Beck Anxiety Inventory; IES, Impact of Event Scale.

NOTE. Positive numbers indicate greater anxiety, depression, or test-related distress among $\varepsilon 4$-positive subjects than $\varepsilon 4$-negative subjects. $P$ values represent a post hoc test, using linear models, that scores differ by $A P O E$ result after adjusting for randomization, age, sex, race, and education.

NOTE. CIs are confidence intervals. Scores were adjusted for age, sex, race, and education. 
providers and test-recipients alike. In fact, blood-draw sessions were shorter in the condensed protocols despite the omission of an opportunity for subjects to address concerns during an in-person education session. The time savings was attributable primarily to having subjects mail family history and personal medical information in advance rather providing this information for the first time during the blood-draw session. These findings are encouraging, given how medical providers may expect escalating requests for genetic testing in the near future. Findings of noninferiority may be explained by prior work showing that motivations for testing are myriad [21,22]. Our condensed protocol was less scripted, and may have provided more opportunities for addressing individual goals rather than generalized concerns that may be of less relevance to specific test recipients. If so, test recipients may benefit from the incorporation of a decision aid into the educational brochure that helps them set realistic expectations about the ability of testing to satisfy those outcomes [23]. Alternatively, genetic susceptibility testing may pose lower psychological risks to volunteer populations than often speculated. Other randomized trials of genetic testing disclosure have shown no incremental risk to psychological well-being through group education [24] or telephone disclosure [25], but minor increases in anxiety using computer education rather than in-person counseling [26].

This study also compares disclosure protocols administered by genetic counselors to those administered by nongeneticist physicians. While none of the outcomes in this comparison suggested that genetic information was harmful, scores on scales of test-related distress were not consistently within the margin for noninferiority when results were disclosed through a nongeneticist physician rather than a genetic counselor. Inferences from this comparison are limited because there was such a small number of genetic counselors and nongeneticist physicians. Moreover, the genetic counselors were female, had each served as study coordinators at their respective sites and spent more time on average in the disclosure session, whereas the physicians were all male and spent less time on average in the disclosure session. Nevertheless, the differences observed between the CP-GC and CPMD protocols suggest that GCs might be more effective in relieving short-term emotional distress than physicians providing disclosure through the same protocol. Analyses of cases where genetic testing was ordered without a genetics specialist and surveys of genetic counselors suggest that nonspecialists often provide insufficient genetic counseling before testing $[27,28]$. The physicians in our study did not have formal training in medical genetics but they were well versed in explaining the probabilistic nature of $A P O E$ findings, and therefore were not typical of practicing physicians.

Our study has limitations because we excluded individuals with low cognitive testing scores and those with very severe anxiety and depression; and the volunteers who participated tended to be well educated, and (by virtue of their participation) positively inclined toward genetic testing. While we did not specifically track the characteristics of persons who were offered and declined participation, we followed the same recruitment practices as we did in our earlier trials where enrollees were found to be younger and better educated than persons who declined enrollment [29]. Thus individuals who might be less motivated to learn these results, who were experiencing mild cognitive symptoms, who had higher levels of baseline distress, or who were older or less well educated might not show the same results. For individuals receiving genetic risk results for other common complex conditions such as diabetes or heart disease, a different set of outcomes (involving appropriate interpretation and subsequent behaviors) will likely be more important than distress and our study does not address this. The physicians in our study were familiar with communicating genetic risk information and may not be representative of other physicians lacking formal training in genetics. Lastly, noninferiority trials may introduce greater subjectivity and allow fewer protections against bias than superiority trials [14]. Nonetheless, our data challenge the existing recommendations for disclosure of $A P O E$ for the risk of $\mathrm{AD}$ [3], and add evidence that suggests that a condensed pretest educational protocol for the disclosure of potentially distressing genetic risk information about a frightening and untreatable common disease to willing recipients can be safe.

\section{Acknowledgments}

This work was supported by National Institutes of Health (NIH) grants HG002213, HG006500, HD077671, AG013846, HG006993, AG042437, HG005092, AG027841, RR000533, and RR010284. None of the authors report conflicts of interest relevant to this manuscript.

Additional members of the REVEAL Study group are as follows: D. Bhatt, Brigham and Women's Hospital, and Harvard Medical School, Boston; B. Biesecker, National Human Genome Research Institute, Bethesda; D. Blacker, Mass General Hospital/Harvard Medical School and Harvard School of Public Health, Boston; C. Chen, Boston University School of Public Health, Boston; E. Cox, Weill Cornell Medical College, New York; J.G. Davis, Weill Cornell Medical College, New York; L. Farrer, Boston University School of Medicine and Boston University School of Public Health, Boston; P. Griffith, Morehouse School of Medicine, Atlanta; K. Harkins, Perelman School of Medicine, Philadelphia; S. Hiraki, Albert Einstein College of Medicine, Bronx; M. Johnson, Howard University, Washington, DC; S. Johnson, Howard University, Washington, DC; E. Juengst, University of North Carolina School of Medicine, Chapel Hill; J. Karlawish, Perelman School of Medicine, Philadelphia; L. Le, University of Michigan School of Public Health, Ann Arbor; E. McCarty Wood, Perelman School of Medicine, Philadelphia; T. Obisesan, 
Howard University, Washington, DC; S. Post, Stony Brook University, Stony Brook; K. Quaid, Indiana University School of Medicine, Indianapolis; L. Ravdin, Weill Cornell Medical College, New York; D. Roter, Johns Hopkins Bloomberg School of Public Health, Baltimore; R. Stern, Boston University School of Medicine, Boston; A. Sadovnick, University of British Columbia, Vancouver; S. Sami, Case Western Reserve University, Cleveland; P. Sankar, Perelman School of Medicine, Philadelphia; E. Topol, Scripps Research Institute, La Jolla; W. Uhlmann, University of Michigan, Ann Arbor; L. Waterston, Maine Medical Center Research Institute, Portland; L. Wright, Medical College of Georgia, Athens. No compensation was received by these individuals in exchange for their participation beyond the NIH funding cited above.

\section{Supplementary data}

Supplementary data related to this article can be found at http://dx.doi.org/10.1016/j.jalz.2014.10.014.

\section{RESEARCH IN CONTEXT}

1. Systematic review: $A P O E$ genotyping in asymptomatic individuals for risk of Alzheimer's disease (AD) has been controversial for some time, both within the $\mathrm{AD}$ community and as a paradigm for common complex risk assessment in the medical genetics community. We have searched PubMed and other sources for greater than 10 years for published research and opinions in this arena.

2. Interpretation: Over the past decade, there has been a reluctant appreciation that some individuals wish to know their $A P O E$ genotypes for AD risk assessment. Current expert-based recommendations for such disclosures emphasize conventional, time-intensive genetic counseling. To our knowledge, our research provides the only empirical data on more condensed protocols for $A P O E$ genotype disclosure.

3. Future directions: Larger scale studies on the impact of disclosing APOE genotype may more definitively answer the question of safety and benefit of this information.

\section{References}

[1] Green RC, Roberts JS, Cupples LA, Relkin NR, Whitehouse PJ, Brown T, et al. Disclosure of APOE genotype for risk of Alzheimer's disease. N Engl J Med 2009;361:245-54.
[2] International Huntington Association and the World Federation of Neurology Research Group on Huntington's Chorea. Guidelines for the molecular genetics predictive test in Huntington's disease. J Med Genet 1994;31:555-9.

[3] Goldman JS, Hahn SE, Catania JW, LaRusse-Eckert S, Butson MB, Rumbaugh M, et al. Genetic counseling and testing for Alzheimer disease: joint practice guidelines of the American College of Medical Genetics and the National Society of Genetic Counselors. Genet Med 2011;13:597-605.

[4] Teng EL, Chui HC. The Modified Mini-Mental State (3MS). Examination. J Clin Psychiatry 1987;48:314-8.

[5] Christensen KD, Roberts JS, Royal CDM, Fasaye G-A, Obisesan T, Cupples LA, et al. Incorporating ethnicity into genetic risk assessment for Alzheimer disease: the REVEAL Study experience. Genet Med 2008;10:207-14.

[6] Crean S, Ward A, Mercaldi CJ, Collins JM, Cook MN, Baker NL, et al. Apolipoprotein E epsilon4 prevalence in Alzheimer's disease patients varies across global populations: a systematic literature review and meta-analysis. Dement Geriatr Cogn Disord 2011;31:20-30.

[7] Tang MX, Stern Y, Marder K, Bell K, Gurland B, Lantigua R, et al. The APOE-epsilon4 allele and the risk of Alzheimer disease among African Americans, whites, and Hispanics. JAMA 1998;279:751-5.

[8] Beck AT, Epstein N, Brown G, Steer RA. An inventory for measuring clinical anxiety: psychometric properties. J Consult Clin Psychol 1988;56:893-7.

[9] Radloff LS. The CES-D scale: A self-report depression scale for research in the general population. Appl Psychol Meas 1977; 1:385-401.

[10] Santor DA, Zuroff DC, Ramsay JO, Cervantes P, Palacios J. Examining scale discriminability in the BDI and CES-D as a function of depressive sererity. Psychol Assess 1995;7:131-9.

[11] Horowitz M, Wilner N, Alvarez W. Impact of Event Scale: a measure of subjective stress. Psychosom Med 1979;41:209-18.

[12] Payne K, Nicholls S, McAllister M, MacLeod R, Donnai D, Davies LM. Outcome measurement in clinical genetics services: A systematic review of validated measures. Value Health 2008; 11:497-508.

[13] Roberts JS, Cupples LA, Relkin NR, Whitehouse PJ, Green RC. Genetic risk assessment for adult children of people with Alzheimer's disease: the Risk Evaluation and Education for Alzheimer's Disease (REVEAL) Study. J Geriatr Psychiatry Neurol 2005;18:250-5.

[14] Snapinn SM. Noninferiority trials. Curr Control Trials Cardiovasc Med 2000;1:19-21.

[15] Cupples LA, Farrer LA, Sadovnick AD, Relkin N, Whitehouse P, Green RC. Estimating risk curves for first-degree relatives of patients with Alzheimer's disease: the REVEAL Study. Genet Med 2004; 6:192-6.

[16] Piaggio G, Elbourne DR, Altman DG, Pocock SJ, Evans SW. Reporting of noninferiority and equivalence randomized trials: an extension of the consort statement. JAMA 2006;295:1152-60.

[17] Jones B, Jarvis P, Lewis JA, Ebbutt AF. Trials to assess equivalence: the importance of rigorous methods. BMJ 1996;313:36-9.

[18] Collins LM, Schafer JL, Kam C-M. A comparison of inclusive and restrictive strategies in modern missing data procedures. Psychol Methods 2001;6:330-51.

[19] Chung WW, Chen CA, Cupples LA, Roberts JS, Hiraki SC, Nair AK, et al. A new scale measuring psychologic impact of genetic susceptibility testing for Alzheimer disease. Alzheimer Dis Assoc Disord 2009;23:50-6.

[20] Roberts JS, Chen CA, Uhlmann WR, Green RC. Effectiveness of a condensed protocol for disclosing APOE genotype and providing risk education for Alzheimer disease. Genet Med 2012;14:742-8.

[21] Christensen KD, Roberts JS, Uhlmann WR, Green RC. Changes to perceptions of the pros and cons of genetic susceptibility testing after APOE genotyping for Alzheimer disease risk. Genet Med 2011; 13:409-14. 
[22] Roberts JS, LaRusse SA, Katzen H, Whitehouse PJ, Barber M, Post SG, et al. Reasons for seeking genetic susceptibility testing among first-degree relatives of people with Alzheimer disease. Alzheimer Dis Assoc Disord 2003;17:86-93.

[23] Edwards A, Gray J, Clarke A, Dundon J, Elwyn G, Gaff C, et al. Interventions to improve risk communication in clinical genetics: systematic review. Patient Educ Couns 2008;71:4-25.

[24] Calzone KA, Prindiville SA, Jourkiv O, Jenkins J, DeCarvalho M, Wallerstedt DB, et al. Randomized comparison of group versus individual genetic education and counseling for familial breast and/or ovarian cancer. J Clin Oncol 2005;23:3455-64.

[25] Jenkins J, Calzone K, Dimond E, Liewehr D, Steinberg S, Jourkiv O, et al. Randomized comparison of phone versus in-person BRCA1/2 predisposition genetic test result disclosure counseling. Genet Med 2007;9:487-95.
[26] Green MJ, Peterson SK, Baker MW, Harper GR, Friedman LC, Rubinstein WS, et al. Effect of a computer-based decision aid on knowledge, perceptions, and intentions about genetic testing for breast cancer susceptibility: a randomized controlled trial. JAMA 2004; 292:442-52.

[27] Bensend TA, Veach PM, Niendorf KB. What's the harm? Genetic counselor perceptions of adverse effects of genetics service provision by non-genetics professionals. J Genet Couns 2013;:1-16.

[28] Brierley KL, Campfield D, Ducaine W, Dohany L, Donenberg T, Shannon K, et al. Errors in delivery of cancer genetics services: implications for practice. Conn Med 2010;74:413-23.

[29] Roberts JS, Barber M, Brown TM, Cupples LA, Farrer LA, LaRusse SA, et al. Who seeks genetic susceptibility testing for Alzheimer's disease? Findings from a multisite, randomized clinical trial. Genet Med 2004;6:197-203.

\section{Did you know?}

\section{You can track the impact of your article with citation alerts that let you know when your article (or any article you'd like to track) has been cited by another Elsevier-published journal.}

\section{Visit www.alzheimersanddementia.org today!}

